\title{
NOTES ON A NEW ENGLAND ARADID.
}

\author{
By Geo. W. Barber.
}

Bureau of Entomology, U.S. Dept. of Agriculture.

Among the species of the very interesting family Aradidae that occur in New England is Aradus 4-lineatus Say.* It is not uncommon, being found beneath the bark of dead trees, particularly old stumps and logs where the fungus on which it feeds grows abundantly. On this fungus the eggs are laid and the young feed.

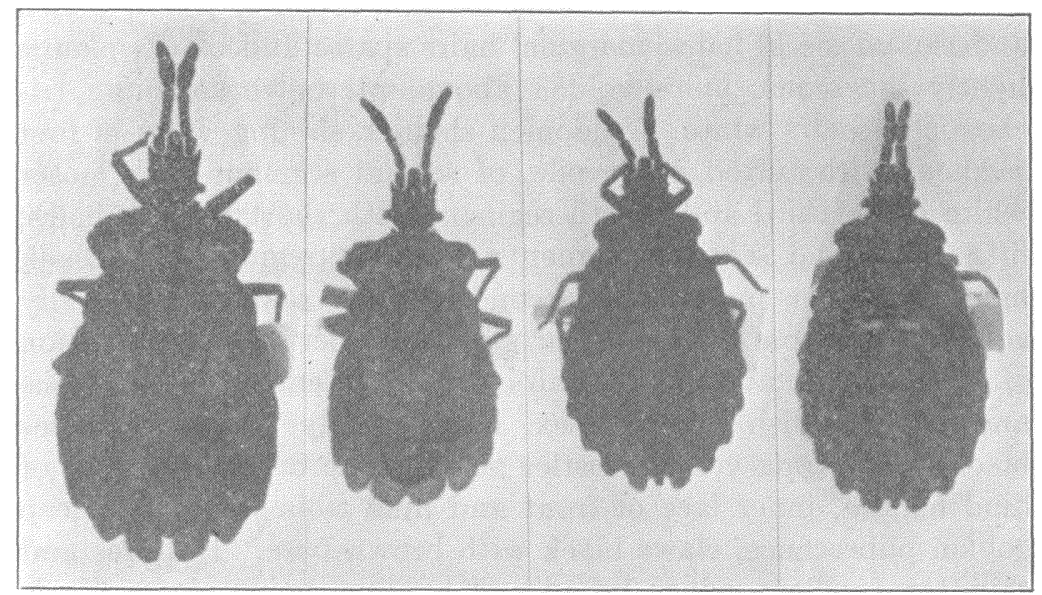

Fig. 1. Aradus 4-lineatus Say. From left to right, adult female, adult male, full-grown nymphs.

The eggs are closely cemented to the fungus and those which I have seen, always laid singly, oviposition continuing for some time. During 1920 one female in a cage deposited 13 eggs from May 16 to June 2. In 1922 eggs were obatined from June 14 to June 18. In all, ten eggs hatched in from 16 to 18 days the average incubation period being 17.8 days. Six first instar nymphs moulted in fron 8 to 13 days, the average length of the first instar being 11.1 days. Males that I confined in cages lived from 28 to 30 days, females from 14 to 35 days.

*Determined by H. M. Parshley. 
Lugger, in the 6th. Rep. Div. Ent. Minnesota. St. Exp. Sta. 1900 p. 40 described the egg of an Aradid, probably Aradus robustus Uhl. as follows; "the eggs glistening white in color are deposited under the bark."

Heidman, 1911-Proc. Ent. Soc. Wash. XIII p. 134 described the egg of an Aradid, Neuroctenus simplex as ;"Egg about $1 \mathrm{~mm}$. long $5 \mathrm{~mm}$. wide; laid in a heap numbering from 20 to 60 or more. Chorion whitish, irregular, coarse, hexagonal; no apical cap; the chorial processes seem to be wanting."

The egg of Aradus 4-lineatus Say is quite different in structure and the habit of oviposition is dissimilar. It differs in structure particularly in the flattened ventral surface and in possessing both a distinct cap and chorial processes, altho the latter are very minute and inconspicuous. The habit of oviposition differs in that all those which I have seen are deposited singly as previously mentioned.

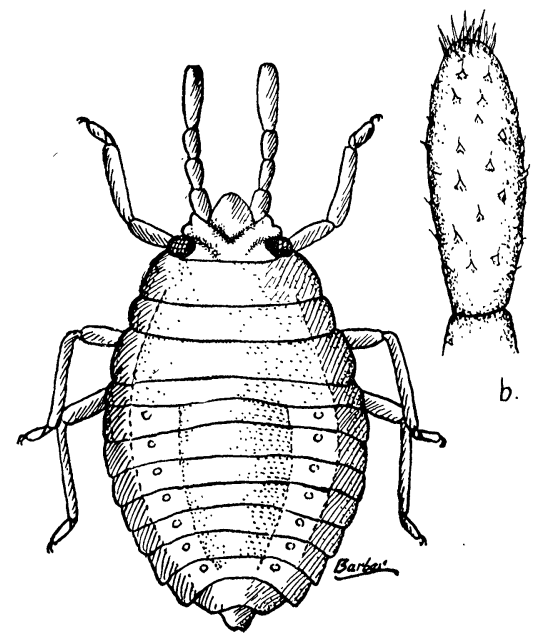

2

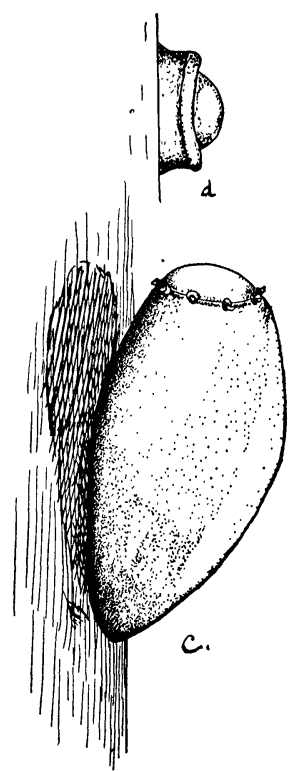

Fig. 2. Aradus 4 lineatus Say. a, first instar nymph; b, apical joint of antennæ of first instar nymph; c, egg, viewed laterally; d, corial process of egg. 
THE EGG.

Length $1.2 \mathrm{~mm}$; width at middle $.8 \mathrm{~mm}$; thickness at middle $.425 \mathrm{~mm}$.

Color, light red, smooth, moderately shining; viewed dorsally oval, narrowing towards the cap; flattened ventrally for a half to three fourths of its surface where it adheres to the fungus, the cap somewhat raised; cap not prominent, chorial processes ten in number, placed in a circle about the cap, minute, cupshaped, raised but little above the chorion, a white hemispherical protuberance sometimes protrudes from the apex.

THE FIRST INSTAR NYMPH.

Length $1.2 \mathrm{~mm}$; width $.7 \mathrm{~mm}$. Color light red, the legs lighter, nearly cream color, femura lighter red, apical joint of antennæ and eyes dark; general aspect of body flattened; head with a groove rising before each eye, curving towards the Posterior line of the head, which it nearly attains, and somewhat towards the median line; eyes moderately prominent; beak scarcely reaching the anterior edge of the third ventral segment; antennæ one third the length of the body, 4-jointed, apical joint widest, as long as the third and fourth together, minutely and sparsely. tuberculate, apically bearing a few very minute hairs; thorax slightly wider than eyes; abdomen evenly rounded at the sides, a third longer than the thorax and somewhat broader; edge of the thorax and abdomen foliaceous. 

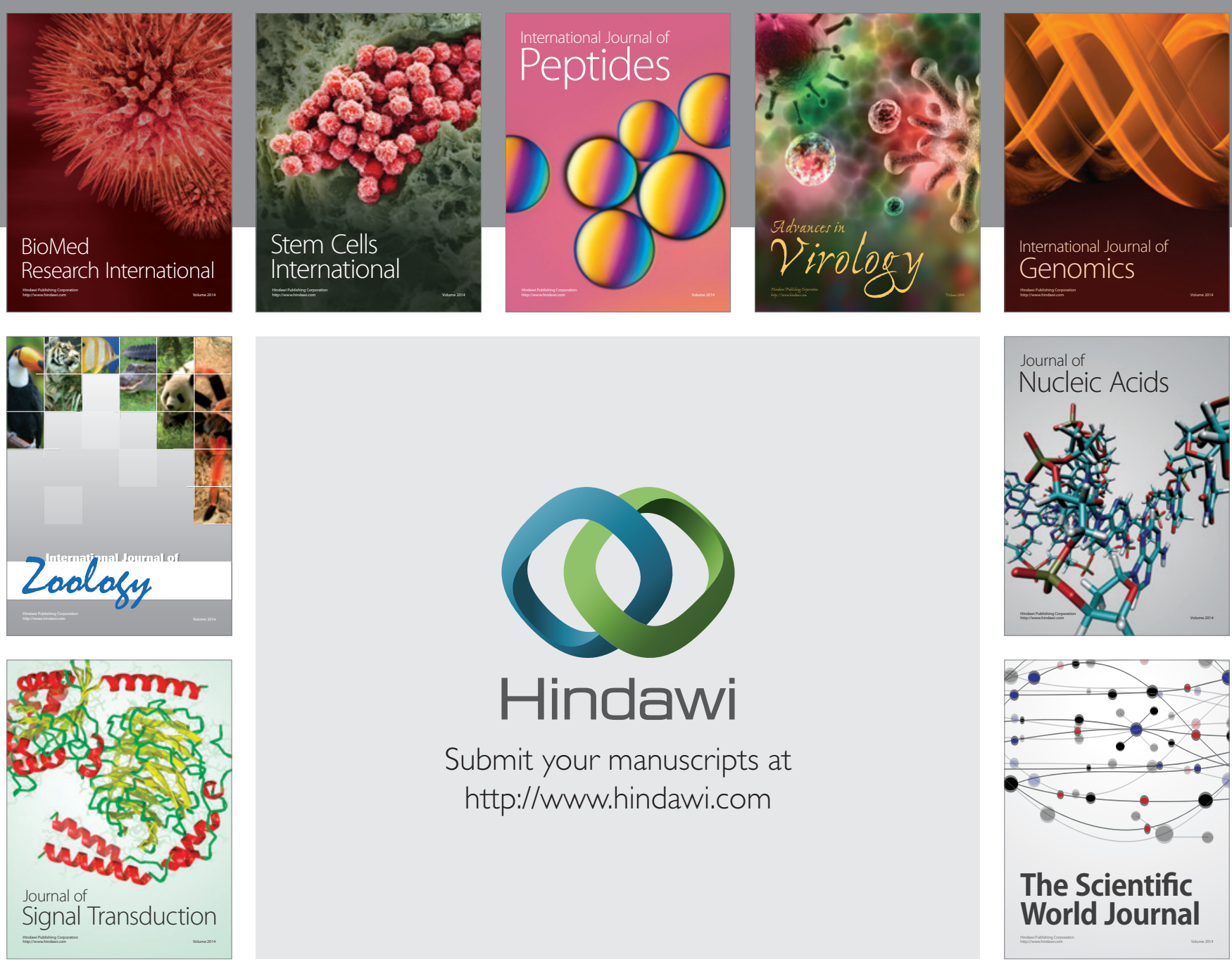

Submit your manuscripts at

http://www.hindawi.com
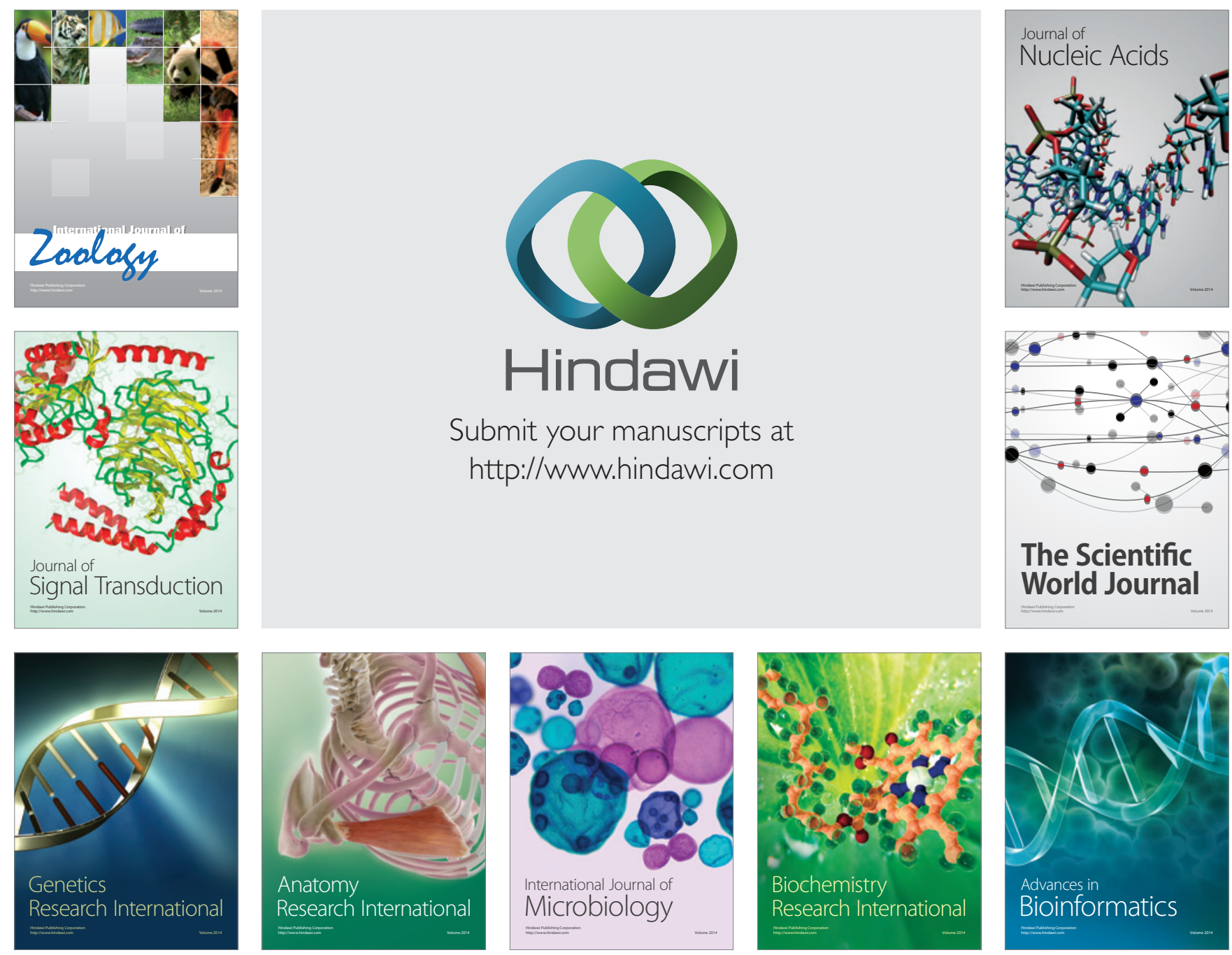

The Scientific World Journal
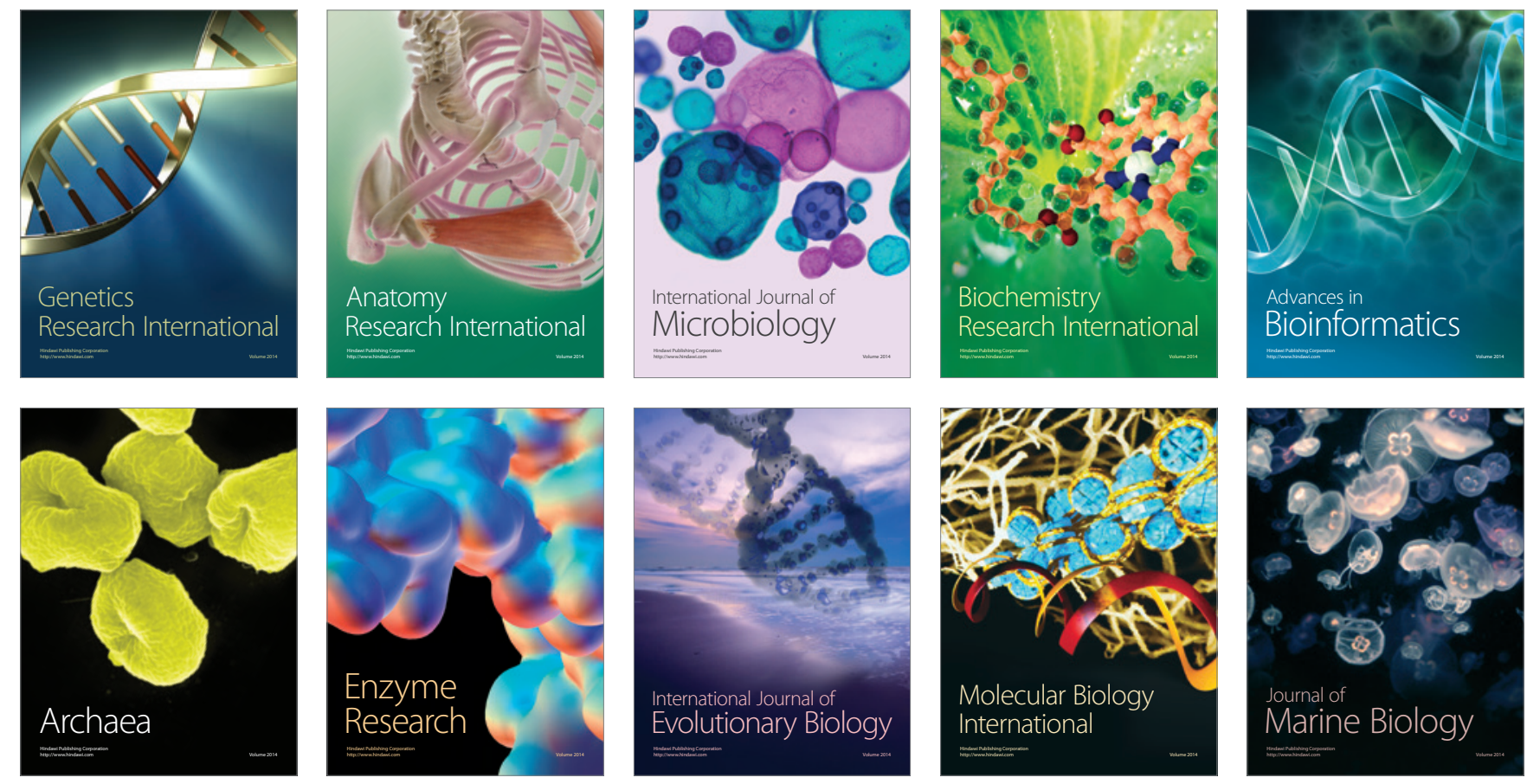